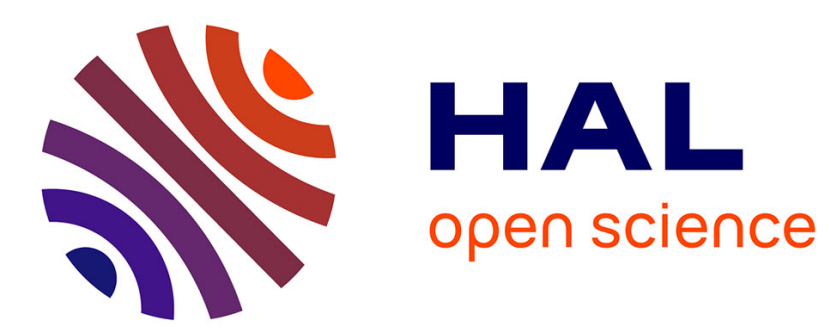

\title{
The role of parasites in ecology and evolution of migration and migratory connectivity
}

\author{
A. P. Møller, T. Szép
}

\section{To cite this version:}

A. P. Møller, T. Szép. The role of parasites in ecology and evolution of migration and migratory connectivity. Journal für Ornithologie = Journal of Ornithology, 2010, 152 (S1), pp.141-150. 10.1007/s10336-010-0621-x . hal-00647968

\section{HAL Id: hal-00647968 \\ https://hal.science/hal-00647968}

Submitted on 4 Dec 2011

HAL is a multi-disciplinary open access archive for the deposit and dissemination of scientific research documents, whether they are published or not. The documents may come from teaching and research institutions in France or abroad, or from public or private research centers.
L'archive ouverte pluridisciplinaire HAL, est destinée au dépôt et à la diffusion de documents scientifiques de niveau recherche, publiés ou non, émanant des établissements d'enseignement et de recherche français ou étrangers, des laboratoires publics ou privés. 
1 The role of parasites in ecology and evolution of migration

$6 \quad{ }^{1}$ Laboratoire d'Ecologie, Systématique et Evolution, CNRS UMR 8079,

$7 \quad$ Université Paris-Sud, Bâtiment 362, F-91405 Orsay Cedex, France;

$8{ }^{2}$ Center for Advanced Study, Drammensveien 78, NO-0271 Oslo, Norway;

9

10

11

12

13

14

15

16

17

18

19

20

21

\section{and migratory connectivity}

\section{A. P. Møller ${ }^{1,2}$ and T. Szép ${ }^{3}$}

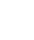

9
${ }^{3}$ Institute of Environmental Science, College of Nyíregyháza,
P. O. Box 166, H-4401 Nyíregyháza, Hungary

Word count: 7509

Correspondence to APM:

$$
\text { Tel: (+33) } 169155688
$$$$
\text { Fax: (+33) } 169155696
$$ 
24 Abstract All organisms are adapted to their native environment, posing

25 problems in terms of fitness costs for individuals that leave this

26 environment. Other species constitute an important coevolving component

27 of this native environment, with more than half of all living organisms

28 being parasites. All host species have evolved behavioral and physiological

29 defenses against parasitism, and all higher organisms have evolved

30 immunity that rely on exposure to novel substances derived from other

31 organisms (antigens) for developing efficient defenses. The evolution of

32 dispersal must have been affected by host-parasite interactions because

33 dispersers and migrants inevitably encounter novel parasite strains to

34 which they are not adapted. Here we provide an overview of bird migration

35 and migratory connectivity viewed in the light of host-parasite interactions.

36 Migratory birds generally show strong site fidelity to both breeding and

37 wintering locations, as evidenced from studies of individuals, estimates of

38 adult survival rates based on breeding or non-breeding captures, and

39 studies of migratory connectivity. Connectivity is closely linked to

40 development of the immune system and regression of immune defense

41 organs. Empirical and theoretical evidence suggests that site fidelity is

42 under stabilizing selection, and that offspring resemble their parents in

43 terms of site fidelity. Populations may diverge in connectivity when the

44 fitness benefits in terms of parasitism exceed the costs. Many species of

45 birds have evolved migratory divides from glacial and post-glacial isolation 
46 that may constitute incipient speciation linked to divergence in parasite

47 faunas and hence in local co-adaptation of hosts and parasites in the

48 breeding and the winter quarters. Migration may play a role in speciation

49 when interbreeding among hosts causes divergence in fitness costs and

50 benefits of parasitism due to local adaptation in breeding and winter areas.

51 These ecological and evolutionary scenarios for migration and migratory

52 connectivity provide a number of testable assumptions and predictions that

53 can form the basis of future research.

55 Keywords: Antigens . Differentiation . Dispersal . Immunity . Local

56 adaptation. Parasitism. Site fidelity. Speciation. Species richness. 


\section{Introduction}

59 Connectivity is defined as the degree of connection between subjects from

60 two or more classes, with migratory connectivity reflecting unique

61 populations of individuals in terms of separate spatial distribution during

62 two or more seasons (Webster et al. 2002). Such connectivity is important

63 for understanding the inter-connected nature of bird migration during

64 different stages of the annual cycle. Connectivity also allows for a better

65 understanding of interactions between environmental conditions at

66 different stages of the annual cycle for life history events, but also for the

67 evolution of the annual cycle. Finally, migratory connectivity has important

68 conservation implications because efficient conservation cannot be

69 achieved without considering the sites of significance for maintaining

70 viable populations throughout the year.

The first extensive analysis of migratory connectivity and its

72 ecological and evolutionary implications was made by Finn Salomonsen

73 (1955), who realized that bird species differ in extent of overlap in

74 distribution between populations for breeding and wintering, and that such

75 divergence is associated with divergent patterns of selection during

76 breeding and winter. Thus, some species have populations with different

77 breeding areas, some with different winter quarters, and some differ with

78 respect to both. Furthermore, such differences are often spatially organized

79 due to leapfrog or cross migration with more northern breeding populations 
80 migrating the longest distances thereby over-flying the breeding and

81 wintering ranges of resident or less migratory populations. These

82 differences in migration are associated with populations with the longest

83 migrations having late spring migration, small body size and the most

84 southern winter quarters. These effects clearly had evolutionary

85 implications for divergence among populations and species as reflected by

86 different subspecies and species (Salomonsen 1955).

87 The main focus of the recent literature on migratory connectivity

88 has been to connect breeding and wintering grounds of different species

89 (reviews in Hobson 2008; Hobson and Wassenaar 2008). This initial

90 research was subsequently followed by detailed studies of carry-over

91 effects allowing for study of the relative effects of environmental

92 conditions during winter and breeding to be estimated, sometimes with a

93 time delay (e. g. Marra et al. 1998; Norris et al. 2004; Sillett et al. 2002;

94 Saino et al. 2004). Migratory connectivity can now be objectively

95 quantified allowing for delineation of separate populations with specific

96 degrees of connectivity between breeding and wintering areas (Ambrosini

97 et al. 2009). Here we will not review this extensive literature on

98 connectivity, but we rather intend to provide a novel general framework for

99 understanding ecology and evolution of migration and migratory

100 connectivity by focusing on parasites and host-parasite coevolution. While

101 time, energy and aerodynamics have playing a fundamental role in 
102 developing models of optimal bird migration (Alerstam 1998; Lindström

103 and Alerstam 1992; Alerstam et al. 2003), there has been little effort

104 attempting to integrate studies of bird migration with predator-prey (e. g.

105 Alerstam and Lindström 1990; Lindström 1990) or parasite-host

106 interactions (Møller et al. 2004a). The reason seems to be that optimality

107 approaches have focused narrowly on energy and aerodynamics, while

108 disregarding all biological interactions. Here we will try to redress this

109 imbalance by making an exhaustive review of the role of parasites in the

110 evolution of bird migration and migratory connectivity because parasitism

111 is the most neglected factor, while simultaneously holding the greatest

112 potential in generating novel hypotheses, predictions and tests.

113 The objective of this review is to provide a theoretical framework for

114 the study of migration, connectivity and parasitism, providing testable

115 assumptions and predictions. The main claim is that parasites and local

116 adaptation by hosts to the parasite community provide a uniquely strong

117 selection pressure maintaining site fidelity to breeding areas and winter

118 quarters, thus ensuring migratory connectivity. The structure of this review

119 is as follows: First, we present evidence suggesting that birds generally are

120 faithful to their breeding and wintering grounds. Second, we propose that

121 adaptation to local parasite communities may explain why migratory birds

122 are faithful to their breeding and wintering grounds. Third, we explore the

123 hypothesis that parasitism may explain why migrants benefit from 
124 traveling long distances. Fourth, we propose ways in which to estimate

125 selection on connectivity and heritability of connectivity based on the

126 assumption that hosts are adapted to local parasite strains at their breeding

127 and wintering grounds. Fifth, we explain why site fidelity breaks down, and

128 why migratory divides evolve and are maintained. Finally, we explore how

129 migration and connectivity may lead to population divergence and

130 speciation. While many of these subjects are as yet only addressed in a

131 cursory manner in the scientific literature, we believe that a general

132 overview is warranted, if for no other reason then as a stimulus to future

133 research.

134

135 Animals are faithful to their breeding and wintering grounds

136 Birds but also other animals are highly faithful to their breeding sites

137 (Greenwood and Harvey 1982; Clobert et al. 2001), with reproductive

138 failure being a major cause of breeding dispersal (Greenwood and Harvey

139 1982; Clobert et al. 2001). Perhaps more surprisingly birds are highly

140 faithful to their wintering sites, often returning year after year to the same

141 location both during migration and in winter (reviews in Berthold 2001;

142 Newton 2008). Traditionally, site philopatry has been explained as arising

143 from the benefits of familiarity with feeding areas. Surprisingly, we have

144 been unable to find a single study demonstrating such fitness advantages of

145 familiarity in migratory birds. 
If migratory connectivity is strong, and breeding and wintering sites

147 of individuals are stable over time, we should expect apparent survival rate

148 to be the same independent of whether estimates are based on captures

149 during breeding or winter. Peach et al. (2001) reported annual adult

150 survival rates of two Palearctic migrants based on captures and recaptured

151 recaptures in the African winter quarters in Malawi. Great reed warblers

152 Acrocephalus arundinaceus had an annual survival rate of $59 \%$, while

153 garden warblers Sylvia borin had an annual survival rate of $54 \%$. These

154 values compare well with estimates based on mark-recapture analyses from

155 the breeding grounds of $65 \%$ and $54 \%$, respectively (Glutz von Blotzheim

156 and Bauer 1991). Furthermore, marsh warblers Acrocephalus palustris have

157 a survival rate of $47 \%$ in winter, and a value of $49 \%$ at the breeding

158 grounds (Kelsey 1989; Cramp and Perrins 1984). Likewise, Sillett and

159 Holmes (2002) reported survival rates based on mark-recapture analyses of

160 American redstarts Setophaga ruticilla from the breeding grounds and the

161 wintering grounds of $46 \%$ and $43 \%$, respectively. Apparent adult survival

162 estimated from winter and breeding captures was very similar and

163 positively correlated among species. This provides evidence of strong

164 connectivity and hence for selection against dispersal.

165 We can learn from the exceptions to the rule that migratory

166 connectivity is strong. So what are these? A prime example is the Arctic

167 tern Sterna paradisaea that forages over vast regions of the Southern 
168 Ocean virtually migrating the entire winter from one site to another thus

169 showing hardly any site fidelity (Egevang et al. 2010). Many other marine

170 birds show similar, albeit less extreme patterns. How can such migration

171 systems with weak connectivity be maintained? Piersma (1997) suggested

172 that certain habitats like coastal areas harbor fewer parasites and vectors

173 than freshwater wetlands, creating a parasite-poor safe haven for migratory

174 birds. Consistent with this interpretation, Mendes et al. (2005) reported

175 lower levels of blood parasite infections in waders living in marine than in

176 freshwater habitats, although this conclusion awaits confirmation in

177 phylogenetic analyses.

178

Why are animals faithful to their breeding and wintering grounds?

180 High levels of site fidelity in migratory birds during breeding and winter

181 raise questions about the nature of the selective agents maintaining such

182 fidelity. Clearly the null expectation would be that migration as such would

183 allow migratory species to disperse long distances at hardly any metabolic

184 cost, simply because they have the morphology that facilitates movement

185 (Belliure et al. 2000). Thus, there much be important selection pressures

186 that prevent migrants from regularly moving long distances between

187 breeding or wintering sites in subsequent years. Here we suggest that few

188 agents other than parasitism constitute sufficiently strong selection to

189 maintain site fidelity. Parasites coevolve with host immunity, and local 
190 adaptation may affect interactions between hosts and parasites. Indeed

191 local adaptation in host-parasite interactions may help stabilize interactions

192 and constrain dispersal of hosts (Kaltz and Shykoff 1998). Any vertebrate

193 host species will be affected by hundreds of species of parasites, if we rely

194 on information from human and veterinary parasitology. Although any

195 given parasite may only show large-scale population structure, the fact that

196 any single host individual has to cope with the entire community of

197 parasites that it encounters implies that hosts only can disperse with

198 significant risks of encountering novel parasite strains. It is this mosaic of

199 local parasite strains that we suggest severely limits the possibilities for

200 host individuals to disperse, and only so when fitness benefits of local

201 reproduction are jeopardized as reflected by reproductive failure

202 (Greenwood and Harvey 1982; Clobert et al. 2001). As an adaptation to

such dispersal there exist empirical evidence showing that longer dispersal

204 distances are associated with increased investment in immunity in great tits

205 Parus major (Snoeijs et al. 2004). Similarly, Møller et al. (2004b) showed

206 in a comparative analysis of common European birds that there is a strong

207 positive association between mean natal dispersal distance and cell-

208 mediated immunity (accounting $28 \%$ of the variance), suggesting that there

209 are immunological costs associated with dispersal. So far we have no

210 information on immunity of birds and site fidelity at the wintering grounds,

211 but we expect similar patterns as reported for the breeding areas. 
A second body of information that can be used to test for benefits of

213 site fidelity concerns the timing of immunological ontogeny. The timing of

214 regression of immune defense organs like the bursa of Fabricius

215 responsible for development of the B-cell repertoire and the thymus

216 responsible for development of T-cells coincides with exposure to all sites

217 visited during the annual cycle and the life cycle of a bird (Møller and

218 Erritzøe 2001). While previous studies had indicated that bursal regression

219 occurred at sexual maturity triggered by increasing levels of sex hormones,

220 that is clearly not the case as shown by regression of the bursa in

221 albatrosses and other long lived species after their have returned to their

222 future breeding site, but before having reached full sexual maturity (Møller

223 and Erritzøe 2001). Thus regression of these immune defense organs and

224 the storage of immunological information as cell memory occur after

staging and wintering sites have been encountered during the first year of

226 life in short-lived species that reproduce during the first year of their life.

227 In contrast, long-lived species do not fully regress these immune defense

228 organs until they have visited their future breeding grounds during the last

229 years of their pre-reproductive life. Thus, these observations suggest why

230 breeding dispersal generally is shorter than natal dispersal, but also how

231 exposure to parasite communities during natal dispersal and migration can

232 be considered a means of "vaccination" against local parasites (exposure to

233 antigens in the environment during the first annual cycle that will allow a 
234 rapid and extensive secondary immune response upon later exposure to

235 these same antigens). Therefore, migrants are not 'tourists that travel to

236 warm climates without vaccination', but well prepared travelers adapted to

237 the environmental conditions encountered in different parts of the world.

238 A third line of evidence consistent with parasites playing a role in

239 local adaption is based on the link between cognitive ability and parasitism.

240 Parasites can sharply reduce brain function and cognitive ability in birds,

241 mammals and humans (reviews in Møller et al. 2005; Eppig et al. 2010).

242 Given that bird migration involves a significant amount of decision making

243 based on assessment of environmental cues, any impaired brain function

244 due to parasitism is likely to have negative consequences for migratory

245 performance. Møller (2010) has recently shown that brain size predicts

246 arrival date of barn swallows to the breeding grounds, and that brain size

247 predicts the time it takes to capture an individual, but also the probability

248 of recapture.

249 Finally, parasites may play an important role in the evolution of

250 connectivity. Large-scale geographical patterns of haemosporidians have

251 shown weak evidence for connectivity being linked to parasitism (Fallon et

252 al. 2006; Durrant et al. 2008; Pagenkopp et al. 2008). In sharp contrast,

253 wintering barn swallows Hirundo rustica in South Africa could with more

254 than $80 \%$ certainty be correctly assigned to communal rosts, showing

255 strong evidence for connectivity (A. P. Møller and T. Szép submitted 
256 manuscript). Therefore, blood parasites may not constitute the best markers

257 for studies of connectivity because they are vector transmitted, and

258 frequent horizontal transfer of blood parasites (e. g. Ricklefs and Outlaw

259 2010) makes this parasite taxon an unlikely candidate for showing such

260 effects.

261

262 Migration and parasitism

263 If bird migration is affected by parasitism and the ability to cope with

264 parasites, we should expect measures of migratory performance to correlate

265 with parasitism and immunity. Indeed, studies of barn swallows from

266 Denmark, Italy and Spain have shown that spring arrival date to the

267 breeding grounds is predicted by the abundance of chewing lice, feather

268 mites and blood parasites in males, but less so in females that compete

269 much less for early arrival (Møller et al. 2004a). Furthermore, arrival date

270 of males, but not females is predicted by T-cell mediated immune response

271 (Møller et al. 2004a). This relationship was causal because experimental

272 manipulation of the intensity of infection by hematophagous mites affected

273 arrival date the subsequent spring (Møller et al. 2004a). Less extensive data

274 for other species also suggest that spring migration, especially among

275 individuals that compete for rapid migration is predicted by parasite load

276 (review in Møller et al. 2004a). 
Furthermore, we should expect that migratory connectivity to play a

278 role in determining individual parasite load, thereby affecting body

279 condition and hence migratory performance. The reason is that individuals

280 the disperse and hence contribute to disrupting migratory connectivity will

281 encounter novel parasites (or parasite strains) to which they are not

282 adapted, thereby reducing the condition of that individual with

283 consequences for ability to endure heavy workloads such as that

284 characterizing long distance migration. Jan von Rönn (2010) has recently

285 shown in studies of barn swallows that heterogeneity in stable isotopes of

286 feathers grown in the African winter quarters is associated with greater

287 diversity and prevalence of blood parasites including Plasmodium. Thus

288 individuals that winter in different areas and/or habitats become infected

289 with Plasmodium parasites that are otherwise not encountered by the

290 population of barn swallows. These results are consistent with predictions

291 concerning winter habitat specificity and parasite-mediated selection

292 against dispersal during winter.

293

294 What are the fitness benefits of migration?

295 Migration has evolved because the associated fitness costs are more than

296 compensated by benefits, and ancestral resident populations may initially

297 have started to migrate as a consequence of intense intraspecific

298 competition (Alerstam and Enckell 1979). Any migrant that moved away 
299 from environments with intense competition would be at a selective

300 advantage, even when such migration was seasonal and only provided a

301 fitness benefit during part of the annual cycle (Alerstam and Enckell 1979).

302 Migratory birds have been shown to be more common than residents at

303 higher latitudes in the northern hemisphere (MacArthur 1959; Herrera

304 1978). This pattern has recently been attributed to the greater benefits of

305 reduced nest predation enjoyed by migrants at northern latitudes, a benefit

306 that residents can only achieve through survival during a cold winter

307 (McKinnon et al. 2010). Here we suggest the alternative hypothesis that

308 lower population density and less favorable conditions for development of

309 parasites at high latitudes may reduce the fitness costs of long distance

310 migration. We can test these alternative explanations by quantifying the

311 fitness consequences of predation and parasitism for migratory individuals

312 breeding at different latitudes.

There are latitudinal gradients in parasites with lower diversity at

314 higher latitudes (Rohde 1992; Guégan et al. 2001; Guernier et al. 2004).

315 Furthermore, parasite virulence decreases with increasing latitude both in

316 humans and in birds (Guernier et al. 2004; Møller et al. 2009). Indeed

317 Møller et al. (2009) showed that this latitudinal decline in parasite-induced

318 mortality was independent of parasite taxon and a range of different

319 ecological factors that have been hypothesized or shown to affect the

320 evolution of parasite virulence. There is also evidence for cell-mediated 
321 immunity of birds being stronger intemperate than in subtropical

322 populations of the same species, with the difference in immunity being

323 positively related to the difference in population density (Møller et al.

324 2006). Transmission of parasites is usually density-dependent (Combes

325 2001), and population density generally decreases at high latitudes

326 (MacArthur 1972), thereby reducing the risk of transmission of parasites.

327 Lower temperatures at high latitudes may delay or prevent development of

328 parasites and vectors, allowing migrants a parasite-free or parasite-poor

329 zone during reproduction when reproductive immuno-suppression may

330 otherwise cause significant parasite-mediated mortality (Folstad and Karter

331 1992). Indeed breeding at high latitudes may also constitute an alternative

332 explanation for why waders wintering in marine habitats have few parasites

333 (Piersma 1997; Mendes et al. 2005) because such species breed at high

334 latitudes.

335

336 Selection for site fidelity to breeding and wintering grounds

337 The basic idea in this review is that migratory connectivity is a phenotypic

338 trait with a genetic basis that can be subject to selection and hence evolve.

339 Thus interspecific variation in connectivity can be considered to have

340 evolved in response to interactions among individuals belonging to

341 different populations. Although selection on migratory connectivity has not

342 yet been estimated, we believe that such analyses are feasible. Because 
343 each new generation of birds contains mutants and phenotypically deprived

344 individuals with inferior migratory performance, we should a priori expect

345 a small fraction of juveniles with an inferior migratory program and low

346 migratory connectivity each generation. Although such individuals may

347 sometimes encounter novel environments with an elevated probability of

348 survival, allowing for colonization of novel environments, most often such

349 deviant phenotypes will be selected against because they have reduced

350 probability of survival relating to lack of local adaptation to the local

351 parasite fauna. Thus we should expect strong selection against deviant

352 wintering grounds and connectivity each generation. A measure reflecting

353 the winter location of migrants that molt during winter is the trace element

354 and stable isotope profiles of feathers (Hobson 2008). In other words, if

355 there is selection for site fidelity during winter, we should expect that the

356 variance in trace element or stable isotope profile of feathers grown in the

357 winter quarters to decrease strongly between yearlings and two year old

358 individuals, and less so in older age classes, and these selection pressures

359 should be directly related to parasite mediated natural selection during

360 winter.

361 If trace element or isotope profile reflects the location during molt

362 in winter, and if offspring winter in the same place as their parents, then we

363 should expect heritability of trace element and isotope profiles. Because

364 dispersal during winter should change the isotope and trace element profile 
365 of an individual from one year to the next, we should expect parasite load

366 to change in parallel. Furthermore, if parasite load is partly determined by

367 winter dispersal, and if both parasite load and isotope and trace element

368 profile are consistent between generations, we should expect positive

369 genetic correlations between parasite load and isotope and trace element

370 profile. We have no data to test these predictions, although feathers

371 collected from parents and offspring would allow such an empirical test.

372 However, repeatability of trace element and stable isotope profiles among

373 years provides an upper limit to heritability. Such repeatability estimates

374 for trace element and stable isotope profiles were high in two different

375 species (Hjernquist et al. 2009; Szép et al. 2003, 2009), suggesting that

376 there is scope for high heritabilities as well.

378 Evolution of migratory polymorphism and population differentiation

379 Many bird species have migratory divides with one part of the entire

380 population migrating in one direction and another part in another direction,

381 usually with separate winter quarters for populations on each side of the

382 migratory divide. For example, many migrants have such divides at the

383 Ural Mountains. Genetic differentiation of many animals in Central Europe

384 reflects Ice Age refugia in the Iberian Peninsula and the Balkans (Hewitt

385 1996). Hence, the location of migratory divides in Europe is non-randomly

386 distributed with disproportionately many species having such divides 
387 located in Central Europe, reflecting secondary colonization following the

388 retreat of the ice following the last glaciations.

There is evidence for genetic differentiation of populations of birds across migratory divides (Chamberlain et al. 2000; Prochazka et al. 2010), suggesting that populations on either side of the divide have been isolated

392 for so long time that they have become partially isolated. We should also

393 expect partial reproductive isolation across migratory divides, as described 394 recently for the blackcap Sylvia atricapilla (Rolshausen et al. 2009).

395 Finally, we should expect significant differences in the parasite fauna

396 across the migratory divide because populations on either side will

397 differentially pick up novel parasites of different geographic origin. Three 398 studies of haemosporidians have shown very little evidence consistent with 399 this last prediction (Bensch and Åkesson 2003; Durrant et al. 2007;

400 Svensson et al. 2007), although frequent horizontal transfer in blood 401 parasites (e. g. Ricklefs and Outlaw 2010) make this parasite taxon an 402 unlikely candidate for showing any such effects.

\section{When does site fidelity break down?}

405 Many species migrate very long distances that exceed the shortest distance 406 between breeding areas and possible wintering areas (Sutherland 1998).

407 This observation is usually interpreted as evidence for lack of optimality, 408 and that constraints may somehow explain apparent mal-adaptive behavior. 
409 An alternative interpretation based on host-parasite interactions and local

410 adaptation is that birds only change their migratory behavior with difficulty

411 because of adaptation to local parasite faunas. Eventually some individuals

412 and later entire populations may change their migratory direction and

413 distance, showing that selection for such change is intense, and that micro-

414 evolution causes rapid changes. We suggest that such changes will proceed

415 more readily when there are no or only very few closely related species co-

416 occurring at the breeding and the novel wintering grounds because there are

417 fewer risks of acquisition of parasites from conspecifics and from closely

418 related hosts.

419 How are migratory divides maintained? Divides can only be

420 maintained if populations are partially reproductively isolation across

421 migratory divides, as described for the blackcap Sylvia atricapilla

422 (Rolshausen et al. 2009). Thus mating across a migratory divide should

423 cause breakdown of local adaptation to parasite communities on either side

424 of the divide at the breeding and the wintering grounds. Therefore, any

425 individual that manages to cross the migratory divide during breeding or

426 winter should be at a selective disadvantage.

427 Finally, we might expect that migratory divides have population

428 consequences if different populations track resources in different parts of

429 the winter quarters, and if different populations of hosts are adapted to

430 different parasites. Species with migratory divides should be better adapted 
431 to local conditions both during breeding and winter than species without

432 migratory divides, because gene flow will tend to break down local

433 adaptations, and such adaptations could be maintained through

434 reproductive isolation across divides. We could also expect that partially

435 genetically isolated populations across divides can better buffer overall

436 population size than a single population subject to unique environmental

437 perturbations in its entire winter range. A potential unique measure of such

438 adaptation is whether species with migratory divides are better able to track

439 changes in environmental conditions than species without divides. We

440 classified bird species as having migratory divides or not using maps in

441 Zink and Bairlein (1987-1995), Cramp and Perrins (1977-1994) and Glutz

442 von Blotzheim and Bauer (1966-1997) as sources. Thus, if two or more

443 populations migrated in different directions, having a clear geographic

444 divide in migratory direction, we classified the species as having a

445 migratory divide. We fully realize that some species may be misclassified

446 as not having migratory divides because of missing information, although

447 that should make our analyses conservative. Although such bias should be

448 more common in rare species with restricted ranges, we found no

449 significant difference in global breeding range size or population size in the

450 Western Palearctic, after controlling for body mass. Consistent with our

451 prediction, population trends across Europe based on the European bird

452 census program (Voříšek 2008) and qualitative trends in population size 
453 across Europe assessed by BirdLife International (2004) differed between

454 species with and without migratory divides (Fig. 1; European bird census:

$455 F=4.40$, d.f. $=1,89, r^{2}=0.05, P=0.039$, slope $(\mathrm{SE})=0.0068(0.0032)$;

456 BirdLife International: $F=3.54$, d.f. $=1,214, r^{2}=0.011, P=0.05$, slope

$457(\mathrm{SE})=0.256(0.136))$. Both analyses showed that species with migratory

458 divides had increasing mean population trends, while species without such 459 divides did not.

460

461

462

463

464

465

466

467

468

469

470

471

472

473

474

\section{FIG. 1 ABOUT HERE}

\section{Migration and speciation}

If populations diverge in migration patterns and migratory connectivity across a migratory divide, this could result in incipient speciation. While several species show divergence at the sub-species level across migratory divides, as initially described by Salomonsen (1955), the extent to which sub-species have evolved as a consequence of bird migration and partial separation of populations in the winter quarters will depend on dispersal and the relative importance of selection in the breeding and the winter range (Lack 1944; Salomonsen 1955). Dispersal is responsible for the mixing of populations, with a single migrant per generation being sufficient to prevent genetic differentiation (e. g. Morjan and Rieseberg 2004). Migratory birds have longer dispersal distances than residents (Paradis et 
475 al. 1999; Belliure et al. 2001), making it less likely that migrants establish 476 genetically isolated populations (Rensch 1933; Mayr 1942). Therefore, we

477 might expect fewer opportunities for isolation of marginal populations in 478 migrants than in residents for a sufficiently long time to allow population 479 genetic differentiation. Indeed, there is a significant negative relationship 480 between subspecies richness and migration distance among birds from the 481 Western Palearctic, after accounting for body size and breeding range size 482 (Phillimore et al. 2006). Thus, subspecies richness is highest in residents, 483 with intermediate levels for short distance migrants, and the lowest levels 484 for long distance migrants.

We hypothesize that speciation and ultimately species richness will 486 increase as a function of parasitism through effects on migratory

487 connectivity. The critical test would assess whether parasite-mediated 488 connectivity as described here preceded formation of subspecies and 489 species. If parasites played a negligible role, we should expect isolation in 490 allopatry (which is the predominant mode of speciation in birds (Mayr 491 1942)) independent of parasite-mediated connectivity to account for such 492 divergence.

494 Time, energy, predation and other alternative hypotheses

495 There are at least three explanations for the evolution and the maintenance 496 of bird migration: energetics, predators and parasites. The evolution of 
497 migration from an ancestral state of residency subsequently may have

498 allowed migrants to exploit seasonal environments that only provide an

499 adequate food supply during part of the year. While time, energy and

500 aerodynamics have playing a fundamental role in developing models of

501 optimal bird migration (Alerstam 1998; Lindström and Alerstam 1992;

502 Alerstam et al. 2003), predator-prey (e. g. Alerstam and Lindström 1990;

503 Lindström 1990) or parasite-host interactions (Møller et al. 2004a) may

504 also play significant roles. There has been little effort attempting to

505 integrate studies of bird migration, and to the best of our knowledge there

506 are no tests attempting to distinguish among these different hypotheses.

507 Such tests are further complicated by the fact that predation differentially

508 affects parasitized and sick individuals (review in Møller 2008), and that

509 parasites have negative effects on cognitive abilities and hence decision

510 making (reviews in Møller et al. 2005; Eppig et al. 2010). Occam’s razor

511 states that simple explanations are more likely than more complex ones.

512 However, we should not forget that if many different phenomena can be

513 explained by a single factor, this explanation seems more likely than

514 having to infer many different factors. We strongly believe that the time

515 has come to devise tests that help discriminate among alternative

516 hypotheses for bird migration. The present review constitutes such a first 517 step. 
To advance this field further we suggest three explicit tests that

519 may help resolve the open question about the evolution of bird migration:

520 (1) Transitions in migratory status. Numerous populations of birds have

521 lost migratory habits partially or completely during the last century alone

522 (Berthold 2001). Has these transitions in migratory behavior resulted in

523 correlated responses in terms of energetics, susceptibility to predation and

524 anti-predator behavior, or parasite load and anti-parasite defenses relative

525 to the ancestral migratory populations? (2) Seasonal variation in migratory

526 preparedness. Migrants are adapted to migration only during part of the

527 year, possibly because such adaptations to migration are costly to maintain

528 year-round. Thus, we believe that a test of whether migrants show a greater

529 extent of seasonality in their energetics, susceptibility to predation and

530 anti-predator behavior, or parasite load and anti-parasite defenses than

531 resident populations of the same species, or resident sister taxa living at the

532 same latitude would constitute a strong test. (3) Quantitative genetics of

533 migration syndromes. Migration has a quantitative genetic basis, and a test

534 of the relative importance of the underlying factors associated with the

535 evolution of migration could be based on a quantification of the magnitude

536 of genetic correlations between migration and energetics, susceptibility to

537 predation and anti-predator behavior, or parasite load and anti-parasite

538 defenses, with this analysis being replicated a reasonable number of times

539 to allow for a rigorous test. 


\section{Discussion}

542 We have reviewed evidence relating to the hypothesis that host-parasite

543 interactions and local adaptation in host-parasite interactions may provide a

544 general explanation for the evolution of migratory connectivity. While the

545 study of host-parasite interactions has played a minor role in ornithology,

546 recent studies of humans suggest that the main cause of mortality is

547 infectious disease (Guernier et al. 2004), and humans have adapted in terms

548 of life history to such spatial patterns of disease prevalence (Guégan et al.

549 2001). A recent study of asexually reproducing bdelloid rotifers escaping

550 the particular threat of virulent parasites to asexual species through

551 migration constitutes an important 'exception that proves the rule' (Wilson

552 and Sherman 2010). We believe that host-parasite interactions have played

553 an equally important role in the evolution of life history and migration of

554 other organisms including birds. Hence, we cannot fully understand the

555 evolution of migration and migratory connectivity unless viewed in the

556 light of host-parasite interactions.

A very large number of studies of bird-parasite interactions is based on hemosporidians. We can trace this preponderance of studies of blood parasites to W. D. Hamilton, who pioneered the role of blood parasites in

560 sexual selection, the maintenance of sex and the maintenance of genetic

561 diversity in hosts and parasites (e. g. Hamilton and Zuk 1982). His 
562 contributions have greatly benefited the field, but also disproportionately

563 focused studies of bird-parasite interactions on blood parasites. This has its

564 disadvantages. Blood parasites are peculiar among parasites in being

565 vector-borne and frequently horizontally transmitted even among distantly

566 related host taxa, thereby eliminating the possibility for tight coevolution.

567 We should not expect as tight coevolution in host-parasite system that rely

568 on both parasites and vectors for transmission rather than parasites alone

569 because 'erroneous' decision-making may happen in both parties involved.

570 Thus, it is hardly surprising that studies of connectivity and genetic

571 population structure of blood parasites across migratory divides of hosts

572 show weak effects. Parasites that are not vector-transmitted, and that also

573 constitute the majority of all parasites (Combes 2001), show much greater

574 evidence of co-adaptation, and studies of the role of parasites in the

575 evolution of bird migration would benefit from a broadening of the

576 taxonomic parasite perspective.

577 While we have attempted to provide a general framework for

578 understanding the evolution of bird migration and migratory connectivity

579 based on host-parasite interactions, obviously many open questions remain.

580 We have to move away from demonstrating connectivity to investigating

581 the basis for phenotypic differences in connectivity among individuals, the

582 extent to which this is heritable, the factors associated with phenotypic

583 plasticity in connectivity, and the patterns of selection affecting 
584 connectivity including age-specific patterns of connectivity. Most

585 importantly, we need to design tests that allow discrimination among the 586 underlying selective factors such as familiarity with resources, parasites

587 and predators. Such studies will require detailed information about

588 migratory connectivity of individuals throughout their lives. So far only a

589 single study has ever investigated phenotypic plasticity in migration

590 (Balbontín et al. 2009). While recent progress in the ability to track

591 migratory animals including birds throughout their annual cycle has caused

592 enthusiasm, such technological progress will only prove useful if combined

593 with careful analyses of pertinent ecological and evolutionary questions. In

594 fact, very few scientists study migrants, very few of these estimate fitness

595 components, and even fewer of these collect information about migration

596 and migratory connectivity of individuals across generations and the

597 underlying mechanisms.

598 In conclusion, we have proposed that host-parasite interactions may

599 constitute a key to understanding ecology and evolution of migration and

600 migratory connectivity, and tests of competing hypotheses may further our

601 understanding of this most fascinating phenomenon. Greater focus on

602 understanding these aspects of migration may be relevant for basic

603 research, but also for the study of emerging diseases and conservation.

604

605 Acknowledgments 
606 J. von Rönn kindly allowed me to cite his research. TSz thank to the OTKA 60769068 grant. 
608 References

609

610 Alerstam T (1998) The development of bird migration theory. J Avian Biol

611 $29: 343-369$

612 Alerstam T, Enckell PH (1979) Unpredictable habitats and evolution of $613 \quad$ bird migration. Oikos 33:228-232

614 Alerstam T, Hedenström A, Åkesson S (2003) Long-distance migration:

$615 \quad$ Evolution and determinants. Oikos 103:247-260

616 Alerstam T, Lindström $\AA$ (1990) Optimal bird migration: The relative 617 importance of time, energy, and safety. In: E. Gwinner (ed) Bird 618 migration: Physiology and ecophysiology. Springer-Verlag, Berlin, $619 \quad$ pp. $331-351$.

620 Ambrosini R, Møller AP, Saino N (2009) A quantitative measure of 621 migratory connectivity. J theor Biol 257:203-211

622 Balbontín J, Møller AP, Hermosell IG, Marzal A, Reviriego M, de Lope F 623 (2009) Individual responses in spring arrival date to ecological 624 conditions during winter and migration in a migratory bird. J Anim 625 Ecol 78:981-989

626 Belliure J, Sorci G, Møller AP, Clobert J (2000) Dispersal distances predict 627 subspecies richness in birds. J Evol Biol 13:480-487 
628 Bensch S, Åkesson S (2003) Temporal and spatial variation of Haematozoan in Scandinavian willow warblers. J Parasitol 89:388-

630 391.

631 Berthold P (2001) Bird migration. Oxford University Press, Oxford, UK

632 BirdLife International (2004) Birds in Europe: population estimates, trends and conservation status. BirdLife International, Cambridge, UK

634 Chamberlain CP, Bensch S, Feng X, Åkesson S, Andersson T (2000) Stable isotopes examined across a migratory divide in Scandinavian 636 willow warblers (Phylloscopus trochilus trochilus and Phylloscopus trochilus acredula) reflect their African winter quarters. Proc R Soc

Clobert J, Nichols JD, Danchin E, Dhondt A (eds) (2001) Dispersal.

641 Combes C (2001) Parasitism: The ecology and evolution of intimate 642 interactions. University of Chicago Press, Chicago, IL

Cramp S, Perrins CM (eds) (1977-1994) The birds of the Western Palearctic. Vols. 5-9. Oxford University Press, Oxford, UK

645 Durrant KL, Marra PP, Fallon SM, Colbeck GJ, Gibbs HL, Hobson KA, 646 Norris DR, Bernik B, Lloyd VL, Fleischer RC (2008) Parasite assemblages distinguish populations of a migratory passerine on its breeding grounds. J Zool 274:318-326 
649 Durrant KL, Reed JL, Jones PJ, Dallimer N, Cheke RA, McWilliam AN, 650 Fleischer RC (2007) Variation in haematozoan parasitism at local and landscape levels in the red-billed quelea Quelea quelea. J Avian

652 Biol 38:662-671

653 Egevang C, Stenhouse IJ, Phillips RA, Petersen A, Fox JW, Silk JRD

654 (2010) Tracking of Arctic terns Sterna paradisaea reveals longest 655 animal migration. Proc Natl Acad Sci USA 107:2078-2081

Eppig C, Fincher CL, Thornhill R (2010) Parasite prevalence and the worldwide distribution of cognitive ability. Proc R Soc B (in press)

658 Fallon S, Fleischer R, Graves G (2006) Malarial parasites as geographical 659 markers in migratory birds? Biol Lett 2:213-216

660 Folstad I, Karter AJ (1992) Parasites, bright males, and the 661 immunocompetence handicap. Am Nat 139:603-622

662 Glutz von Blotzheim UN, Bauer KM (eds) (1966-1997) Handbuch der 663 Vögel Mitteleuropas. AULA Verlag, Wiesbaden, Germany

664 Greenwood PJ, Harvey PH (1982) Natal and breeding dispersal in birds. 665 Ann Rev Ecol Syst 13:1-21

666 Guégan J-F, Thomas F, Hochberg M, de Meeus T, Renaud F (2001)

667 Disease diversity and human fertility. Evolution 55:1308-1314

668 Guernier V, Hochberg ME, Guégan J-F (2004) Ecology drives the 669 worldwide distribution of human diseases. PLoS Biol 2:740-746 
670 Hamilton WD, Zuk M (1982) Heritable true fitness and bright birds: a role 671 for parasites? Science 218:384-387

672 Herrera C (1978) Breeding distribution pattern of European migrant birds:

673 MacArthur theme reexamined. Auk 95:496-509

674 Hewitt GM (1996) Some genetic consequences of ice ages, and their role in 675 divergence and speciation. Biol J Linn Soc 58:247-276

676 Hjernquist MB, Veen T, Font L, Klaassen M (2009) High individual repeatability and population differentiation in stable isotope ratios in 678 winter-grown collared flycatcher Ficedula albicollis feathers. J

679 Avian Biol 40:102-107

680 Hobson KA (2008) Using endogenous and exogenous markers in bird 681 conservation. Bird Cons Int 18:S174-S199

Hobson KA, Wassenaar LI (eds) (2008) Tracking animal migration with 683 stable isotopes. Academic Press, London, UK

684 Kaltz O, Shykoff JA (1998) Local adaptation in host-parasite systems. 685 Heredity 81:361-370

Kelsey MG (1989) A comparison of the song and territorial behaviour of a 687 long-distance migrant, the marsh warbler Acrocephalus palustris, in summer and winter. Ibis 131:403-414

Lack D (1944) Ecological aspects of species-formation in passerine birds. Ibis $86: 260-286$ 
691 Lindström $\AA$ (1990) The role of predation risk in stopover habitat selection 692 in migrating bramblings, Fringilla montifringilla. Behav Ecol 1:102$693 \quad 106$

694 Lindström Å, Alerstam T (1992) Optimal fat loads in migrating birds: A 695 test of the time-minimization hypothesis. Am Nat 140:477-491

696 MacArthur RH (1959) On the breeding distribution pattern of North 697 American migrant birds. Auk 76:318-325

MacArthur RH (1972) Geographical ecology. Harper and Row, New York, 699

700

701

702

703

704

705

706

707

708

709

710

711
NY

Marra PP, Hobson KA, Holmes RT (1998) Linking winter and summer events in a migratory bird by using stable-carbon isotopes. Science 282:1884-1886

Mayr E (1942) Systematics and the origin of species. Columbia University Press, New York, NY

McKinnon L, Smith PA, Nol E, Martin JL, Doyle FI, Abraham KF, Gilchrist HG, Morrison RIG, Bêty J (2010) Lower predation risk for migratory birds at high latitudes. Science 327:326-327

Mendes L, Piersma T, Lecoq M, Spaans B, Ricklefs RE (2005) Diseaselimited distributions? Contrasts in the prevalence of avian malaria in shorebird species using marine and freshwater habitats. Oikos 109:396-404 
712 Møller AP (2008) Interactions between interactions: Predator-prey, parasite-host and mutualistic interactions. N Y Acad Sci 1133:180186.

Møller AP (2010) Brain size, head size and behavior of a passerine bird. J Evol Biol 23:625-635

Møller AP, Arriero E, Lobato E, Merino S (2009) A meta-analysis of parasite virulence in nestling birds. Biol Rev 84:567-588

Møller AP, de Lope F, Saino N (2004a) Parasitism, immunity and arrival date in a migratory bird. Ecology 85:206-219

Møller AP, Erritzøe J (2001) Dispersal, vaccination and regression of immune defence organs. Ecol Lett 4:484-490

723

724

725

726

727

728

729

730

731

732

733

Møller AP, Erritzøe J, Garamszegi LZ (2005) Coevolution between brain size and immunity in birds: Implications for brain size evolution. $\mathrm{J}$ Evol Biol 18:223-237

Møller AP, Martin-Vivaldi M, Merino S, Soler JJ (2006) Densitydependent and geographical variation in bird immune response. Oikos 115:463-474

Møller AP, Martin-Vivaldi M, Soler JJ (2004b) Parasitism, host immune response and dispersal. J Evol Biol 17:603-612

Morjan CL, Rieseberg LH (2004) How species evolve collectively: implications of gene flow and selection for the spread of advantageous alleles. Mol Ecol 13:1341-1356 
734 Newton I (2008) The migration ecology of birds. Academic Press, London, 735 UK

736

737

738

739

740

741

742

743

744

745

746

747

748

749

750

751

752

753

754

755 Reproductive effort, molting latitude and feather color in a migratory songbird. Science 306:2249-2250

Pagenkopp KM, Klicka J, Durrant KL, Garvin JC, Fleischer RC (2008) Geographic variation in malarial parasite lineages in the common yellowthroat (Geothlypis trichas). Cons Genet 9:1577-1588

Paradis E, Baillie SR, Sutherland WJ, Gregory RD (1998) Patterns of natal and breeding dispersal in birds. J Anim Ecol 67:518-536

Peach WJ, Hanmer DB, Oatley TB (2001) Do southern African songbirds live longer than their European counterparts? Oikos 93:235-249

Phillimore AB, Freckleton RP, Orme CDL, Owens IPF (2006) Ecology predicts large-scale patterns of phylogenetic diversification in birds Am Nat 168:220-229.

Piersma T (1997) Do global patterns of habitat use and migration strategies co-evolve with relative investments in immunocompetence due to spatial variation in parasite pressure? Oikos 80:623-631

Procházka P, Stokke BG, Jensen H, Fainová D, Bellinvia E, Fossøy F, Vikan JR, Bryja J, Soler M (2010) Low genetic differentiation in a long-distance migratory bird across Europe. Biol J Linn Soc (in press) 
756 Rensch B (1933) Zoologische Systematik und Artbildungsprobleme. Verh Deutsch Zool Gesellsch 1933:19-83

758 Ricklefs RE, Outlaw DC (2010) A molecular clock for malaria parasites. 759 Science 329:226-229

760 Rohde K (1992) Latitudinal gradients in species diversity: The search for 761 the primary cause. Oikos 65:514-527

762

763

764

765

766

767

768

769

770

771

772

773

774

775

Rolshausen G, Segelbacher G, Hobson KA, Schaefer HM (2009)

Contemporary evolution of reproductive isolation and phenotypic divergence in sympatry along a migratory divide. Curr Biol 19:20972101

Saino N, Szép T, Ambrosini R, Romano M, Møller AP (2004) Ecological conditions during winter affect sexual selection and breeding in a migratory bird. Proc R Soc Lond B 271:681-686

Salomonsen F (1955) The evolutionary significance of bird-migration. Biol Medd Kgl Dan Vidensk Selsk 22 (6):1-62

Sillett TS, Holmes RT (2002) Variation in survivorship of a migratory songbird throughout its annual cycle. J Anim Ecol 71:296-308

Sillett TS, Holmes RT, Sherry TW (2002) Impacts of a global climate cycle on population dynamics of a migratory songbird. Science 288:20402042 
776 Snoeijs T, Van de Casteele T, Adriaensen F, Matthysen E, Eens M (2004) dispersal in a songbird. Biol Lett 271:S199-S201

779

780

781

782

783

784

785

786

787

788

789

790

791

792

793

794

795

796

A strong association between immune responsiveness and natal

Sutherland WJ (1998) Evidence for flexibility and constraint in migration systems. J Avian Biol 29:441-446

Svensson LM, Ruegg KC, Sekercioglu CH, Sehgal RN (2007) Widespread and structured distributions of blood parasite haplotypes across a migratory divide of the Swainson's thrush (Catharus ustulatus). J. Parasitol 93:1488-1495.

Szép T, Møller AP, Vallner J., Kovács B, Norman D (2003) Use of trace elements in feathers of sand martin Riparia riparia for identifying moulting areas. J Orn 34:307-320

Szép T, Hobson KA, Vallner J, Kovács B, Szabó DZ, Møller AP (2009) Comparison of trace element and stable isotope approaches to the study of migratory connectivity: An example using two hirundine species breeding in Europe and wintering in Africa. J Orn 150:621636

von Rönn J (2010) Migration and blood parasites in barn swallows. PhD thesis, Max-Planck-Institute for Evolutionary Biology, Plön

Voříšek P (2008) Trends of common birds in Europe, 2008 update, computation procedure and data quality control in details. EBCC, 
Pargue, Czech Republic. URL:

798 http://www.ebcc.info/index.php?ID=362 (accessed 14 October 2009)

799 Webster MS, Marra PP, Haig SM, Bensch S, Holmes RT (2002) Links

800 between worlds: Unraveling migratory connectivity. Trends Ecol

801 Evol 17:76-83

802 Wilson CG, Sherman PW (2010) Anciently asexual bdelloid rotifers escape 803 lethal fungal parasites by drying up and blowing away. Science 804 $327: 574-576$

805 Zink G, Bairlein F (1987-1995) Der Zug europäischer Singvögel. Vols 1-3. 806 Aula Verlag, Wiesbaden, Germany

807 
808 Legend to figure

809

810 Fig. 1 Mean (SE) population trends for European breeding birds with

811 and without migratory divides, based on population trends from the

812 European bird census program (Voř́̌šek et al. 2008)

813 
814 Fig. 1

815

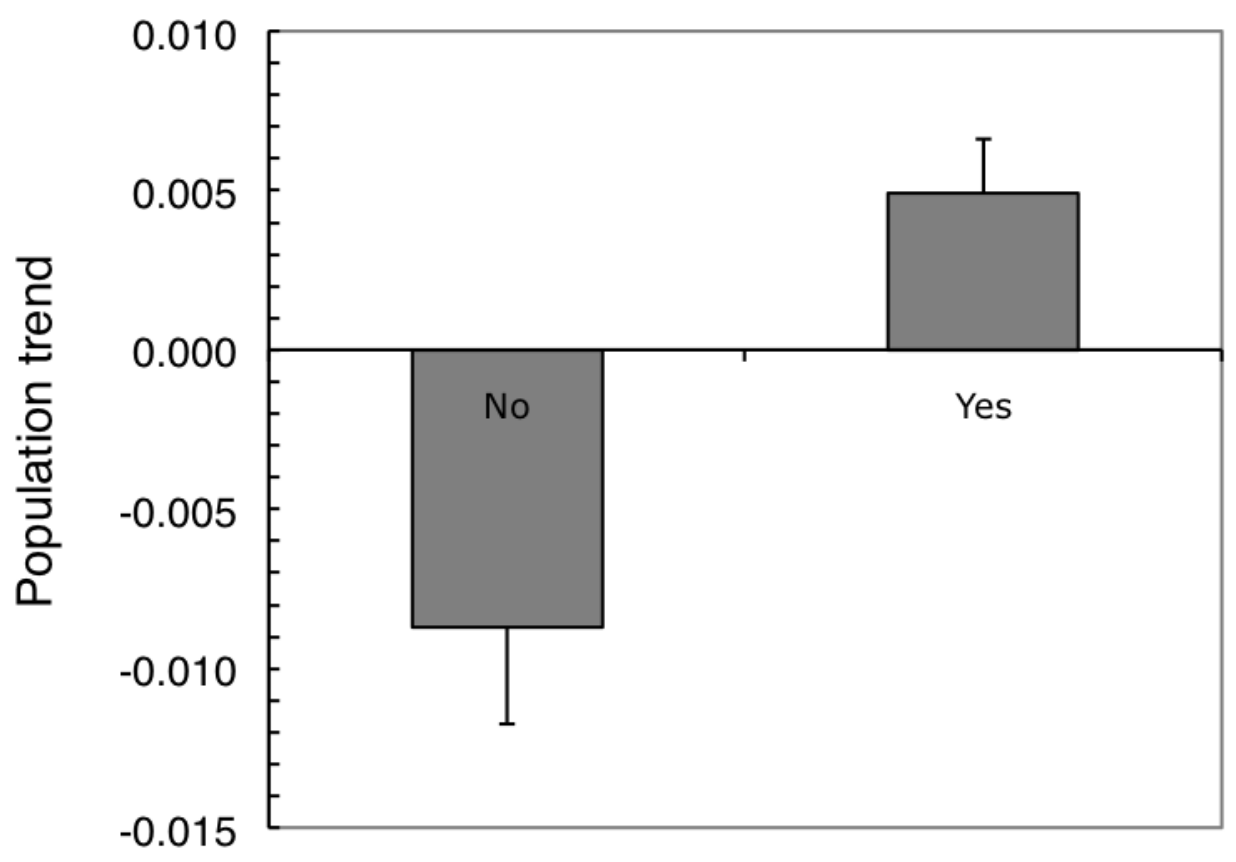

816

Migratory divide 
817 